\title{
TOKSISITAS SENYAWA ANALOG KALKON 3'-METOKSIASETOFENON MENGGUNAKAN METODE BRINE SHRIMP LETHALITY TEST (BSLT)
}

\author{
Kurniati $^{1}$, Yuharmen ${ }^{2}$, Adel Zamri \\ 1. Mahasiswa Program S1 Kimia FMIPA-Universitas Riau \\ 2. Dosen Jurusan Kimia FMIPA-Universitas Riau \\ Fakultas Matematika dan Ilmu Pengetahuan Alam Universitas Riau \\ Kampus Binawidya, Pekanbaru, 28293, Indonesia \\ E-mail: adel.zamri@lecturer.unri..ac.id
}

\begin{abstract}
ABSTRAK
Senyawa kalkon merupakan prekursor dari flavonoid yang penting sebagai antioksidan. Kalkon memiliki berbagai bioaktivitas seperti antikanker, antimikroba, antijamur, antitumor dan anti-inflmasi. Pada penelitian ini dilakukan sintesis senyawa $(E)$-1-(3'-metoksifenil)-3-(3-nitrofenil)prop-2en-1-on dengan metode iradiasi gelombang mikro dan menggunakan katalis basa KOH. Senyawa yang dihasilkan diuji kemurniannya dengan KLT, uji titik leleh dan analisis HPLC serta telah dikarakterisasi dengan spektroskopi UV, FTIR, ${ }^{1} \mathrm{H}-\mathrm{NMR}$ dan MS serta diuji toksisitasnya dengan metode Brine Shrimp Lethality Test (BSLT). Senyawa ini menunjukkan aktivitas toksisitas yang kurang baik dengan nilai $\mathrm{LC}_{50}>200 \mu \mathrm{g} / \mathrm{mL}$.
\end{abstract}

Kata kunci: kalkon, microwave dan sintesis.

\section{PENDAHULUAN}

Perkembangan yang menarik dibidang farmakologis dari bahan alam adalah senyawa kalkon yang merupakan golongan penting dari flavonoid (Choudhary et al., 2011). Senyawa kalkon merupakan prekursor dari flavonoid yang penting sebagai antioksidan (Espinoza et al., 2012). Kalkon memiliki berbagai bioaktivitas seperti antikanker, antioksidan, dan antimikroba (Sharma and Joshi, 2012). Selain itu juga sebagai antijamur, antitumor dan anti-inflmasi (Chen et al., 2013). Aktivitas biologis kalkon, selain disebabkan oleh gugus karbonil $\alpha, \beta$ tak jenuh, juga dipengaruhi oleh subtituen yang terikat pada kedua cincin aromatiknya (Kamble et al., 2011), seperti halogen, hidroksi, metoksi, nitro, maupun metil (Rahmadhona, 2014; Brahmana, 2014; Handayani, 2014; Sofiana, 2014, Tillah, 2014 \& Perdana, 2012).

Keberadaan senyawa kalkon yang memiliki aktivitas biologis di alam sangat terbatas dibandingkan dengan senyawa flavonoid lainnya, selain itu juga variasi strukturnya relatif sedikit, sehingga untuk mengisolasinya terdapat kesulitan, seperti membutuhkan biaya yang banyak dan waktu yang lama. Solusi untuk mengatasi kekurangan tersebut yaitu dengan cara sintesis. Senyawa turunan kalkon dapat disintesis melalui kondensasi aldol atau lebih spesifik melalui kondensasi Claisen-Schmidt dari suatu keton aromatik dengan aldehid aromatik.

Penelitian ini mensintesis senyawa kalkon dengan menggunakan bahan baku aldehid aromatik yaitu senyawa 3-nitrobenzaldehid dengan suatu turunan keton aromatik 3metoksiasetofenon.

\section{METODOLOGI PENELITIAN}

\section{Alat dan Bahan}

Alat-alat yang digunakan dalam penelitian ini adalah microwave Samsung ME109F, alat pengukur titik leleh Fisher Johns (SMP 11Stuart $\left.{ }^{\circledR}\right)$, lampu UV 254/366 nm (Camag $\left.{ }^{\circledR}\right)$, HPLC (Shimadzu LC Solution jenis kolom Shim-pack VP-ODS dengan panjang dan diameternya yaitu 150x4,6 $\mathrm{mm}$ ), spektrofotometer UV (Genesys 10SUV-VIS v4.0022L9N175013), spektrofotometer FTIR (Shimadzu, IR Prestige-21), spektroskopi ${ }^{1} \mathrm{H}$ NMR (Agilent $500 \mathrm{mHz}$ ), spektroskopi Massa (MS Waters LCT premier XE mode positif), peralatan sintesis dan uji toksisitas yang umum digunakan di Laboratorium Sintesis Organik.

Bahan-bahan yang digunakan dalam penelitian ini adalah: 3-metoksiasetofenon (Merck), 4-nitrobenzaldehida (Merck), kalium hidroksida, asam klorida, plat KLT $\mathrm{GF}_{254}$, 
akuades, indikator universal, telur udang (Artemia salina Leach), air laut, etilasetat, nheksana, metanol, etanol absolut, kloroform dan dimetilsulfoksida (DMSO).

\section{Rancangan Penelitian}<smiles>COc1cccc(C(C)=O)c1</smiles><smiles>O=Cc1cccc([N+](=O)[O-])c1</smiles>

Sintesis senyawa kalkon dilakukan dalam satu tahap reaksi melalui kondensasi ClaisenSchimdt dengan menggunakan senyawa awal 4nitrobenzaldehid dan 3-metoksi asetofenon dengan katalis basa $(\mathrm{KOH})$ seperti terlihat pada skema reaksi berikut:

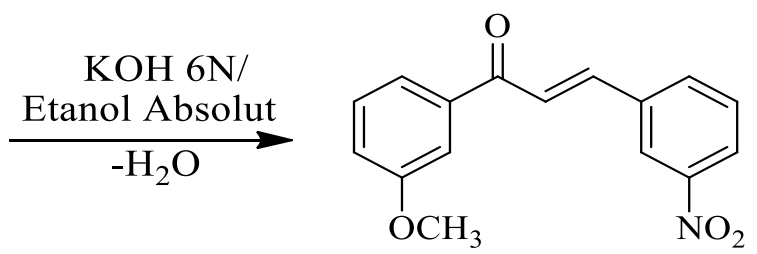

Gambar 1. Sintesis senyawa kalkon

\section{Sintesis senyawa kalkon}

Sebanyak $5 \mathrm{mmol}$ 3-metoksiasetofenon ditempatkan dalam wadah Erlenmeyer $125 \mathrm{~mL}$, kemudian ditambahkan $5 \mathrm{~mL}$ larutan kalium hidroksida $6 \mathrm{~N}$. Setelah itu, sebanyak $5 \mathrm{mmol} 4-$ nitrobenzaldehid dan $5 \mathrm{~mL}$ etanol absolut ditambahkan ke dalam Erlenmeyer. Campuran ini diiradiasi gelombang mikro selama 1-12 menit dengan daya 180 watt. Reaksi dipantau melalui uji KLT setiap 1 menit. Setelah itu, sebanyak $15 \mathrm{~mL}$ akuades dingin ditambahkan ke dalam campuran dan $\mathrm{pH}$ campuran dinetralkan dengan menambahkan asam klorida 3N. Kemudian campuran didiamkan. Endapan yang terbentuk disaring menggunakan pompa vakum dan dicuci dengan akuades dan n-heksana dingin, kemudian direkristalisasi dengan etanol. Produk yang diperoleh diuji kemurniannya dengan uji KLT, titik leleh dan analisis HPLC.

Uji toksisitas dengan metode Brine Shrimp Lethality Test (BSLT)

Sampel sebanyak $20 \mathrm{mg}$ dilarutkan dalam 2 $\mathrm{mL}$ methanol (larutan induk, konsentrasi 10000 $\mu \mathrm{g} / \mathrm{mL}$ ), kemudian dari larutan induk dibuat konsentrasi yang berbeda $1000 \mu \mathrm{g} / \mathrm{mL}, 100$ $\mu \mathrm{g} / \mathrm{mL}, 10 \mu \mathrm{g} / \mathrm{mL} 1 \mu \mathrm{g} / \mathrm{mL}$ dan $0,1 \mu \mathrm{g} / \mathrm{mL}$ dengan cara pengenceran bertingkat. Kemudian disiapkan vial $5 \mathrm{~mL}$ yang sudah dikalibrasi untuk masing-masing konsentrasi. Sampel dipipet ke dalam masing-masing vial sebanyak $0,5 \mathrm{~mL}$, lalu pelarut diuapkan hingga mengering. Selanjutnya, ke dalam masing-masing vial ditambahkan $50 \mu \mathrm{L}$ DMSO. Sebanyak 10 ekor larva udang dimasukkan ke dalam vial tersebut dan ditambah air laut hingga batas kalibrasi 5 $\mathrm{mL}$. Tingkat toksisitas diukur dengan cara menghitung jumlah larva udang yang masih hidup dalam selang waktu 24 jam. Pengujian dilakukan sebanyak tiga kali pengulangan dengan perlakuan yang sama untuk masingmasing konsentrasi. Data yang diperoleh dianalisis untuk menentukan nilai $\mathrm{LC}_{50}$ dengan metode kurva menggunakan tabel analisis probit.

\section{HASIL DAN PEMBAHASAN \\ Sintesis senyawa kalkon}

Penelitian ini mensintesis senyawa analog kalkon yang diperoleh dengan mereaksikan senyawa 3-metoksiasetofenon dan senyawa aldehid aromatik 3-nitrobenzaldehid menggunakan katalis basa $\mathrm{KOH}$ dengan metode iradiasi gelombang mikro. Pelarut yang digunakan adalah etanol absolut karena lebih mudah didapatkan dan tingkat keracunannya lebih rendah dibandingkan pelarut organik lainnya. Selain itu, etanol absolut dapat membantu menyerap air hasil samping dari reaksi kimia yang terjadi.

Sintesis yang telah dilakukan menghasilkan senyawa kalkon dengan rumus molekul $\mathrm{C}_{16} \mathrm{H}_{13} \mathrm{NO}_{4}$ dan berat molekul sebesar 283,08. Senyawa kalkon berupa padatan berwarna kuning dengan berat sebesar $0,52 \mathrm{~g}$ dan rendemen yang dihasilkan sebesar $36 \%$. Sifat fisik dari senyawa kalkon yang dihasilkan dapat dilihat pada Tabel 1. 
Tabel 1. Sifat fisika senyawa kalkon

\begin{tabular}{cccccc}
\hline Senyawa & $\begin{array}{c}\text { Rumus } \\
\text { molekul }\end{array}$ & Berat molekul & Warna & Rendemen $(\%)$ & Ttik leleh $\left({ }^{\circ} \mathrm{C}\right)$ \\
\hline Kalkon & $\mathrm{C}_{16} \mathrm{H}_{13} \mathrm{NO}_{4}$ & 283,08 & Kuning & 37 & $117-118$ \\
\hline
\end{tabular}

Analisis kemurnian senyawa kalkon dilakukan menggunakan KLT, titik leleh dan HPLC. Analisis kemurnian dengan KLT dilakukan menggunakan eluen yang bervariasi dan perbandingan yang berbeda. Senyawa kalkon menunjukkan satu noda pada plat KLT. Noda pada KLT diamati dengan bantuan lampu UV ( $\lambda 254 \mathrm{~nm}$ dan $366 \mathrm{~nm}$ ). Analisis kemurnian dengan titik leleh menunjukkan bahwa senyawa tersebut memiliki range titik leleh sebesar $1^{\circ} \mathrm{C}$. Analisis kemurnian senyawa kalkon menggunakan HPLC dilakukan pada panjang gelombang $224 \mathrm{~nm}$ dan $365 \mathrm{~nm}$ menunjukkan satu puncak dominan pada $t_{R}=16,615$ menit. Berdasarkan data analisis kemurnian tersebut menunjukkan bahwa senyawa kalkon telah murni.<smiles>COc1cccc(C(=O)/C=C/c2cccc([N+](=O)[O-])c2)c1</smiles>

Gambar 2. Struktur dan penomoran senyawa kalkon

Struktur senyawa kalkon yang telah murni dikarakterisasi menggunakan spektroskopi UV, FTIR, ${ }^{1} \mathrm{H}-\mathrm{NMR}$ dan MS. Spektrum UV senyawa kalkon memperlihatkan adanya serapan maksimum pada pada panjang gelombang 207 nm yang menunjukkan adanya ikatan rangkap pada cincin benzen, pada panjang gelombang $221 \mathrm{~nm}$ menunjukkan adanya ikatan rangkap pada cincin A aromatik yang terkonjugasi dengan gugus karbonil dan pada panjang gelombang $289 \mathrm{~nm}$ menunjukkan adanya ikatan rangkap pada cincin B aromatik.

Spektrum FTIR senyawa kalkon memperlihatkan adanya serapan pada bilangan gelombang $3068,88 \mathrm{~cm}^{-1}$ yang menunjukkan adanya gugus $\mathrm{C}-\mathrm{H}$ aromatik, pada bilangan gelombang 1527,69 $\mathrm{cm}^{-1}$ menunjukkan adanya gugus $\mathrm{C}=\mathrm{C}$ terkonjugasi, pada bilangan gelombang $1660,78 \mathrm{~cm}^{-1}$ menunjukkan adanya gugus karbonil $(\mathrm{C}=\mathrm{O})$ dan pada bilangan gelombang 1284,65 $\mathrm{cm}^{-1}$ menunjukkan adanya gugus metoksi (O-C).

Spektrum ${ }^{1} \mathrm{H}-\mathrm{NMR}$ senyawa kalkon menunjukkan bahwa jumlah proton dari senyawa tersebut sesuai dengan yang diharapkan, dapat dilihat pada Tabel 2.

Tabel 2. Spektrum ${ }^{1} \mathrm{H}-\mathrm{NMR}$ senyawa kalkon

Berat molekul kalkon ditunjukkan oleh spektrum massa yang dihitung sebagai $\mathrm{C}_{16} \mathrm{H}_{13} \mathrm{NO}_{4}[\mathrm{M}+\mathrm{H}]^{+}$pada 284 , sedangkan yang ditemukan adalah 283,9. Berdasarkan puncak

\begin{tabular}{cc}
\hline $\begin{array}{c}\text { Nomor } \\
\text { Atom }\end{array}$ & $\begin{array}{c}\text { Senyawa }\left(\mathbf{C K}_{3}\right) \\
\boldsymbol{\delta}_{\mathbf{H}}(\mathbf{p p m})\end{array}$ \\
\hline 1 & - \\
2 & $8,51(\mathrm{~s})$ \\
3 & - \\
4 & $8,27(\mathrm{dd})$ \\
5 & $7,45(\mathrm{t})$ \\
6 & $7,93(\mathrm{~d})$ \\
$\mathrm{C} \alpha$ & $7,64(\mathrm{~m}, \mathrm{H} \alpha, \mathrm{J}=15,5 \mathrm{~Hz})$ \\
$\mathrm{C} \beta$ & $7,84\left(\mathrm{~d}, \mathrm{H}_{\beta}, \mathrm{J}=16 \mathrm{~Hz}\right)$ \\
$1^{\prime}$ & - \\
$2^{\prime}$ & $7,62(\mathrm{~m})$ \\
$3^{\prime}$ & $3,89(\mathrm{~s})\left(\mathrm{OCH} \mathrm{H}_{3}\right)$ \\
4 & $7,18(\mathrm{~m})$ \\
$5^{\prime}$ & $7,57(\mathrm{t})$ \\
6 & $7,63(\mathrm{~m})$ \\
\hline
\end{tabular}

ion molekul yang dihasilkan spektrum MS dan yang dihitung secara teoritis terlihat selisih nilai yang dihasilkan kecil. Hal ini menunjukkan senyawa hasil sintesis telah murni dan mempunyai struktur sesuai dengan yang diharapkan.

\section{Uji toksisitas}

Uji aktivitas toksisitas senyawa kalkon dilakukan dengan menggunakan metode Brine Shrimp Lethality Test (BSLT). Hasil uji toksisitas dari senyawa kalkon pada konsentrasi 1000, 100, 10,1 dan $0,1 \mu \mathrm{g} / \mathrm{mL}$ terhadap larva Artemia salina Leach yang dianalisis dengan metode analisis probit tingkat potensi toksisitas senyawa kalkon dengan nilai $\mathrm{LC}_{50}$ sebesar 6,606 x $10^{6} \mu \mathrm{g} / \mathrm{mL}$. Pada metode Brine Shrimp 
Lethality Test (BSLT), suatu tanaman atau hasil isolasi dianggap menunjukkan aktivitas sitotoksik bila mempunyai nilai $\mathrm{LC}_{50}$ kecil dari $1000 \mu \mathrm{g} / \mathrm{mL}$, sedangkan untuk senyawa murni dianggap menunjukkan aktivitas sitotoksik bila mempunyai nilai $\mathrm{LC}_{50}$ kecil dari $200 \mu \mathrm{g} / \mathrm{mL}$ (Meyer, 1982). Berdasarkan hasil uji aktivitas toksisitas, senyawa kalkon tidak positif berpotensi sebagai senyawa antikanker karena memiliki nilai $\mathrm{LC}_{50}>200 \mu \mathrm{g} / \mathrm{mL}$

\section{KESIMPULAN DAN SARAN}

Berdasarkan hasil penelitian yang telah dilakukan, maka dapat diambil kesimpulan bahwa senyawa kalkon diperoleh melalui reaksi kondensasi aldol Claisen-Schmidt menggunakan katalis basa $(\mathrm{KOH})$ dibawah kondisi iradiasi microwave. Rendemen yang dihasilkan yaitu 37\%. Hasil karakterisasi menggunakan spektroskopi UV, FTIR, ${ }^{1} \mathrm{H}-\mathrm{NMR}$ dan MS menunjukkan bahwa senyawa yang diperoleh dari hasil penelitian adalah murni dan merupakan senyawa kalkon dengan struktur yang diharapkan. Senyawa kalkon memiliki toksisitas dengan nilai $\mathrm{LC}_{50}$ sebesar 6,606 x $10^{6}$ $\mu \mathrm{g} / \mathrm{mL}$, hasil tersebut menunjukkan bahwa senyawa kalkon tidak positif berpotensi sebagai senyawa antikanker

\section{DAFTAR PUSTAKA}

Brahmana, E.M. 2014. Sintesis, Uji Antibakteri dan Uji Toksisitas beberapa Analog Kalkon Tersubstitusi Halogen. Tesis. Universtas Riau, Pekanbaru.

Chen, Y.H., Wang, W.H., Lin, Z.Y and Chern, C.Y. 2013. Evaluation of the AntiInflammatory Effect of Chalcone and Chalcone Analogues in a Zebrafish Model. Molecules. 18: 2052-2060.

Choudhary, A and Juyal, V. 2011. Synthesis of Chalcone and Their Derivatives as Antimicrobial Agents. International Journal of Pharmacy and Pharmaceutical Science. 3(3): 125-128.

Espinoza, J.C., Rodriguez, L.M., Nevarez, G.V and Camacho, A. 2012. Synthesis, Experimental and Theoretical Study of the Spectroscopic Properties in (2E)-3-\{3- methoxy-4-[(3-methyl

but-2-en-1-

yil)oxy]phenyl $\}-1-(3,4,5-$

trimethoxyphenyl)prop-2-en-1-one.

Journal of Molecular Structure. 1020: 8895.

Handayani, S., Teruna, H. Y and Zamri, A. 2014. Sintesis Analog Kalkon (E)-3-(2klorofenil)-1-(4'-metoksifeil)-prop-2-en1-on dan Uji Toksisitas dengan Metode Brine Shrimp Lethality Test (BSLT). Jurnal Indonesian Chemia Acta. 4(1): 1720.

Kamble, V.M., Hatnapure, G.D., Keche, A.P., Birajdar, S., Patil, S.G., Tale, R.H., Rodge, A.H., Turkar, S.S. and Gour, K. 2011. Sintesis and Biological Evaluation of a Novel Series of Methoxylated Chalcones as Antioxidant and Antimicrobial agents. Journal. Chemistry. Pharmceutical. Research. 3(6):639-648.

Meyer, B.N.R., Ferrigni, J.E., Putnam, L.B., Jacosen, D.E., Nicholas, J.L and Laughin, M.C. 1982. Brine Shrimp: A Convenient General Bioassay for Active Plant Constituens . Journal of Medical Plant Medica. 45: 31-34.

Perdana, F., Eryanti, Y and Zamri, A. 2013. Sintesis dan Uji Toksisitas Senyawa Analog Kalkon Para. Repository Universitas Riau.

Rahmadhona, S. 2014. Sintesis dan Uji Toksisitas Analog 3'-Bromo Kalkon. Repository Universitas Riau .

Sofiana, A., Balatif, N and Zamri, A. 2014. Sintesis dan Uji Toksisitas Senyawa Kalkon (E)-1-(2-hidroksifenil)-3-(4metoksifenil) prop -2 - en -1 - on. Repository Universitas Riau.

Tillah, M and Zamri, A. 2014. Sintesis dan Uji Toksisitas Senyawa Kalkon Turunan 4'Metil Asetofenon. Repository Universitas Riau. 